\title{
Imaging Procedures for Colorectal Cancer
}

\author{
Bettina Baeßler David Maintz Thorsten Persigehl \\ Department of Radiology, University Hospital of Cologne, Cologne, Germany
}

\section{Keywords}

Colorectal cancer - Computed tomography, CT .

Magnetic resonance imaging, MRI .

Positron emission tomography, PET . Ultrasound

\section{Summary}

Background: Radiological imaging plays an important role in the setting of staging, follow-up, and imagingguided treatment of colorectal carcinoma (CRC). Methods: This review aims to summarize the current state of the art of the different radiological imaging procedures in CRC including an overview over recently published national and European guidelines and consensus statements concerning the imaging of CRC patients. Results and Conclusion: Radiological imaging is widely embedded in national and international guidelines, and structured reporting is recommended.

(c) 2016 S. Karger GmbH, Freiburg

\section{Introduction}

Different imaging procedures encompassing the whole spectrum of radiological techniques are used in patients suspected or known to suffer from colorectal cancer (CRC). These techniques thus play an important role in primary diagnostics, staging, evaluation of treatment response, follow-up, and even for minimally invasive interventions.

Over the last years, there have been new developments in imaging $\mathrm{CRC}$, including the rapid technological evolution of multidetector helical computed tomography (MDCT), the novel application of CT colonography, improvements in magnetic resonance imaging (MRI) with development of novel sequence techniques, an increasing use of positron emission tomography (PET)-CT, and novel imaging-guided interventional procedures [1].
The present review summarizes the current state-of-the-art imaging in CRC including an overview over recently published national and European guidelines and consensus statements for the clinical management of CRC patients [2-5].

\section{Screening and Primary Diagnostics}

Various screening tests are currently available for CRC and different screening strategies are recommended by several health care advisory committees [1]. Despite some controversies regarding the optimal screening test, there is broad agreement across several national and international guidelines concerning the use of radiological methods in primary diagnostics.

According to the German S3 guideline [2] as well as to the European Registration of Cancer Care (EURECCA) colorectal consensus document [3], CT colonography (virtual colonoscopy), which represents a potential alternative to optical colonoscopy, is only recommended as a second-line imaging procedure for patients with incomplete colonoscopy. Although several studies demonstrated a high sensitivity of $100 \%$ for the detection of carcinomas and of $87.9 \%$ for the detection of adenomas $\geq 10 \mathrm{~mm}[6,7]$, sensitivity for smaller adenomas was lower and, overall, data concerning a comparison of CT colonography to colonoscopy are sparse. In addition, the lacking ability for removal of adenomas, poor standardization, and the radiation exposure during CT colonography prevents the technique from being recommended as an alternative first-line screening method $[2,8]$.

Non-invasive colonography by MRI has been shown to be equally feasible compared to CT colonography for detecting adenomas, thereby lacking radiation exposure. However, data currently are too sparse for any recommendation of MR colonography for screening purposes [8].

Barium enema (single-contrast or double-contrast), which had been extensively used for screening and diagnostic purposes in the past, does not play any significant role in the present diagnostic workup of CRC. It is recommended only as a third-line method in cases where colonoscopy is not possible or contraindicated and CT colonoscopy is not available $[3,9]$.

\begin{tabular}{|c|c|}
\hline KARGER & $\begin{array}{l}\text { (c) } 2016 \text { S. Karger GmbH, Freiburg } \\
2297-4725 / 16 / 0323-0166 \$ 39.50 / 0\end{array}$ \\
\hline Fax +497614520714 & \\
\hline $\begin{array}{l}\text { Information@Karger.com } \\
\text { www.karger.com }\end{array}$ & $\begin{array}{l}\text { Accessible online at: } \\
\text { www.karger.com/vis }\end{array}$ \\
\hline
\end{tabular}


Fig. 1. CT images illustrating different $\mathrm{T}$ stages of colon cancer. A cT2, B cT3, and C cT4. Pericolic tumor extension (T3) can be suggested on $\mathrm{CT}$ when the fat planes are blurred (arrow), although this sign is not specific.

Fig. 2. MR images illustrating different $\mathrm{T}$ stages of rectal cancer. A pT1, B cT2, C cT3 $(\mathrm{MRF}=$ mesorectal fascia, involvement negative -).

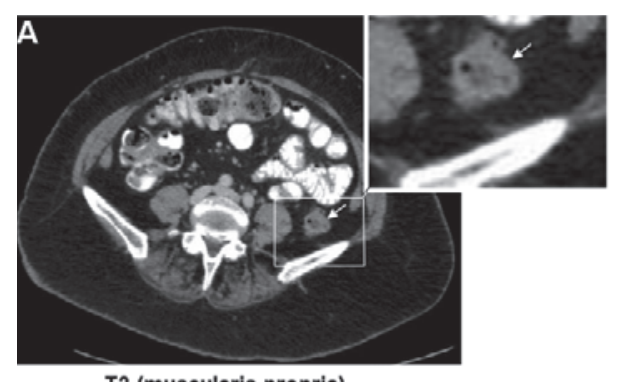

T2 (muscularis propria)

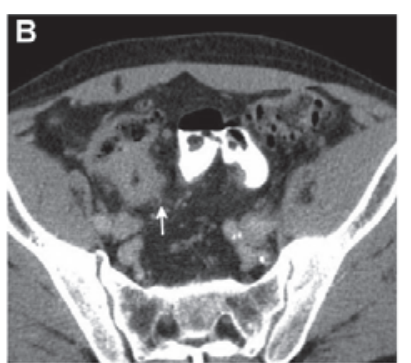

T3 (pericolic tissue)

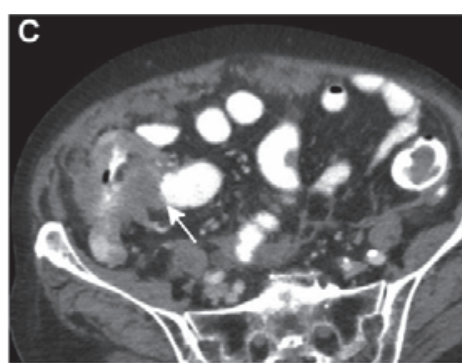

T4 (direct infiltration)

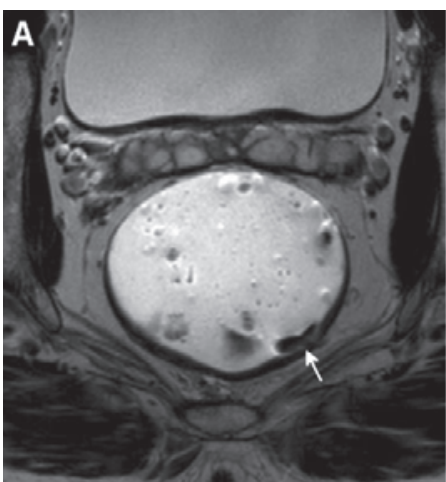

pT1 (submucosa)

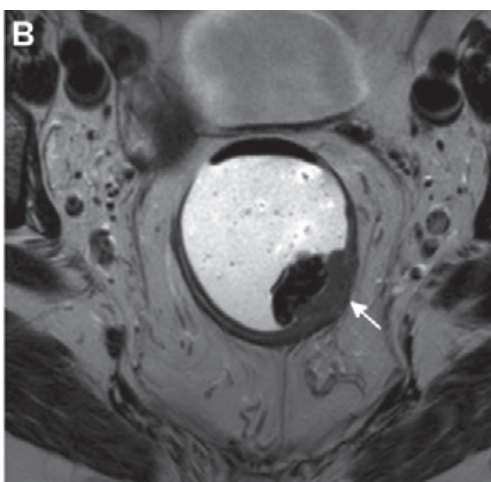

T2 (muscularis propria)

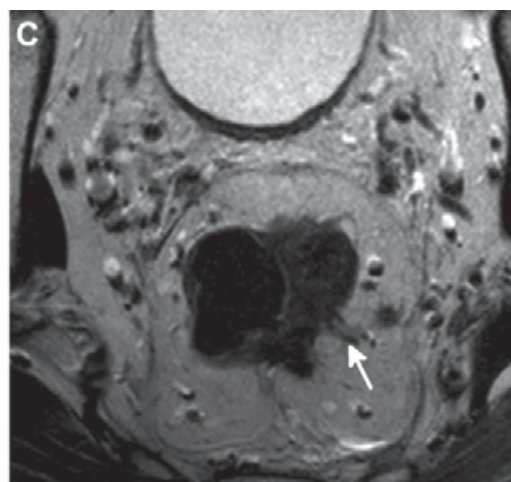

T3 (mesorectal fat)

\section{Staging}

\section{T Staging of Colon Cancer}

For local staging of colon cancer, abdominal CT is widely used and recommended for evaluation of local tumor infiltration $[2,3]$. Abdominal CT allows in many cases to differentiate between tumors restricted to the bowel wall and those exceeding the bowel wall, as well as infiltration of adjacent structures [2]. However, CT is limited in detecting T1 stage due to its reduced soft tissue contrast [3], although in certain cases defining T2 and T3 stages on CT might still be challenging (fig. 1). There is no evidence for an additional diagnostic value of PET-CT in the initial local staging of CRC [2].

\section{T Staging of Rectal Cancer}

Over the past few years, a paradigm shift could be observed concerning the local staging of rectal cancer, leading to the inclusion of MRI in several national and international guidelines. MRI is recommended as the examination of first choice for locoregional staging of rectal cancer $[2,3]$; however, the only exception is that MRI could not reliably differentiate T1 from T2 lesions [10, 11], although this differentiation might be possible in some certain cases (fig. 2). Therefore, endorectal ultrasound (ERUS) is recommended as the first-line diagnostic tool for suspected T1 tumors. In all other cases, MRI is the recommended method of choice.

MRI is especially useful for evaluating the tumor extension into the mesorectal fat and a potential invasion of the mesorectal fascia (MRF) [12-14]. These considerations are of particular importance for further therapeutic decision making and surgical planning
Table 1. T3 subclassification from the rectal wall into the mesorectal fat [3]

\begin{tabular}{ll}
\hline & $\begin{array}{l}\text { Tumor extension beyond } \\
\text { muscularis propria, mm }\end{array}$ \\
\hline T3a & $<1$ \\
T3b & $1-5$ \\
T3c & $>6-15$ \\
T3d & $>15$ \\
\hline
\end{tabular}

which has led to a subclassification of T3 tumors (table 1) $[12,15]$. Especially the distance of the lesion to the MRF has been shown to exhibit an important prognostic value [16], as an infiltration of the MRF or a distance of the tumor to the MRF of $\leq 1 \mathrm{~mm}$ (threatened $\leq 2 \mathrm{~mm}$ ) at MRI is associated with a higher risk of local recurrence $[2,5,17,18]$.

For evaluating the involvement of the MRF, MRI using phasedarray surface coils at $1.5 \mathrm{~T}$ or $3.0 \mathrm{~T}$ is the method of choice [3]. It is widely recommended to routinely acquire $\mathrm{T} 2$-weighted sequences with a slice thickness of $1-3 \mathrm{~mm}$ of the primary tumor. The routine use of endorectal filling is not recommended due to the potential reduction of the distance to the MRF [5] but might be helpful in case of known T1 or T2 stage by previous ERUS for tumor detection. ERUS and PET-CT are not accurate in predicting an involvement of the MRF $[3,19]$. MDCT might represent an alternative method [20], although it has a low diagnostic value in low-seated tumors and especially in those located in the low anterior rectal wall [3].

MRI is also the method of choice for measuring the distance between the anorectal junction and the distal part of the tumor as well as for determining the length of the tumor, and it is reliable in 
Fig. 3. $N$ staging using the novel DWIBS technique. A small lymph node on T2-weighted (T2w) imaging (A; arrow) shows restricted diffusion on DWIBS imaging (B; arrow) suspicious for metastatic disease which might be not detected on T2w only.

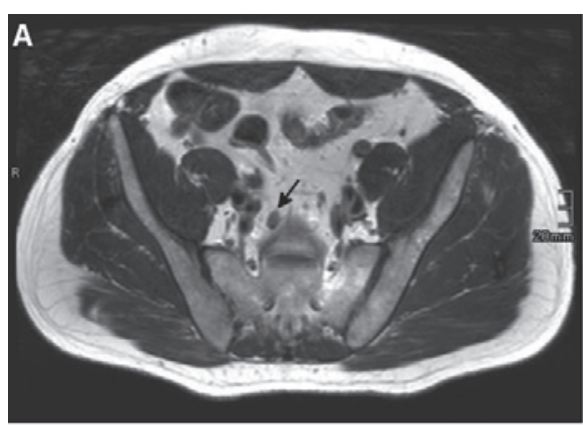

T2w

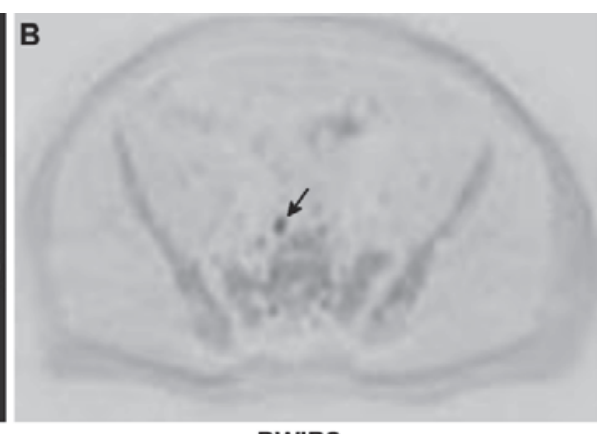

DWIBS

Fig. 4. $M$ staging: pulmonary metastases. Chest X-ray of a female CRC patient in A a.p. and $\mathbf{B}$ lateral view showing suspect intrapulmonary nodules in the left upper and lower lobes (black arrows). C Corresponding CT of the same patient, clearly depicting the pulmo-
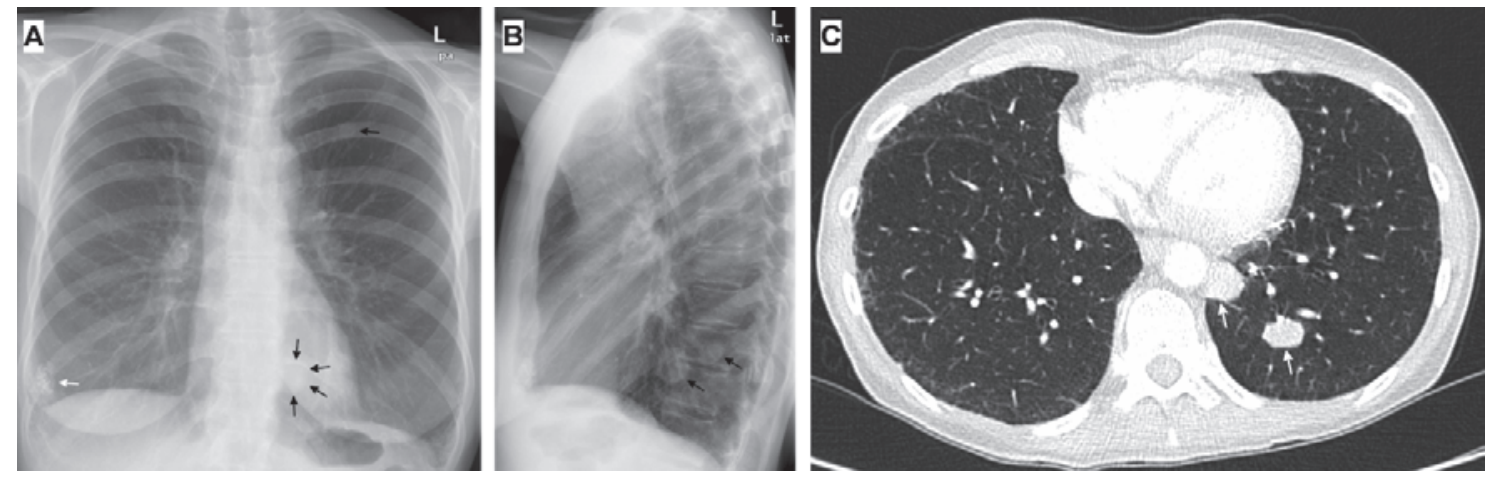
nary metastases (white arrows). Please note the additional calcified fibroadenoma in the right breast on the chest X-ray (A; white arrow).

assessing sphincter infiltration $[3,21]$. Moreover, reasonable accuracy has been demonstrated for the assessment of extramural venous invasion in the preoperative setting using MRI [22].

\section{$N$ Staging of CRC}

Identifying nodal involvement is still a diagnostic dilemma for the radiologist, and all routinely available radiological methods exhibit an unsatisfactory sensitivity and specificity (74-78\%) regarding this issue $[2,3]$. Similarly, fluorodeoxyglucose (FDG)-PET has shown disappointing results for $\mathrm{N}$ staging in $\mathrm{CRC}[3,23]$.

Size does not represent a reliable criterion for nodal involvement, as on the one hand, there might be reactive lymph node enlargement, and on the other hand, there might be microscopic metastatic involvement in nodes even smaller than $5 \mathrm{~mm}$ [2]. More reliable methods for identifying nodal metastases are based on morphological features, e.g. irregularity of the lymph node borders, the presence of a round shape, or signal heterogeneity within the node $[3,24]$.

Recently, a novel MRI technique has been introduced which appears very promising for the detection of suspicious lymph nodes. First described by Takahara et al. [25], the diffusion-weighted imaging with background body signal suppression (DWIBS) technique (fig. 3) provides functional data about tumor cellularity and appears to be instrumental in the detection of also smaller, at least suspicious lymph nodes [26, 27]. However, future studies will have to show the incremental value of DWIBS regarding the detection of nodal metastases in the setting of CRC.

\section{$M$ Staging of $C R C$}

At the time of the initial diagnosis, distant metastases are present in about $25 \%$ of colon cancers and in about $18 \%$ of rectal cancers, of which 19\% (15\%) represent liver metastases and 3\% (4\%) pulmonary metastases, respectively [2]. Therefore, preoperative M staging is important to rule out distant metastases.

There exists a certain disagreement between different national and international guidelines with respect to the M staging of CRC. The EURECCA colorectal consensus document recommends a contrast-enhanced abdominal CT for primary $\mathrm{M}$ staging of CRC and a chest CT as routine workup [3]. Target ultrasound, MRI, or PET-CT represent second-line tools when CT is not unequivocal with respect to liver metastases [3].

In contrast, the German $\mathrm{S} 3$ guideline recommends an abdominal ultrasound and a chest X-ray (fig. 4A) as baseline tools for $\mathrm{M}$ staging in CRC [2]. A chest CT should be performed in the case of suspected pulmonary metastases (fig. 4B). A CT of the abdomen and pelvis is only recommended in the case of unclear findings or if distant metastases or an infiltration into adjacent organs are suspected. [2]. Table 2 summarizes the imaging methods recommended for preoperative staging by the German S3 guideline.

As abdominal CT is routinely performed for locoregional staging of colon cancer, however, the clinical practice somewhat deviates from these recommendations at least in this entity, and it is widely accepted that the major strength of abdominal CT lies in the detection of distant metastases - with a high accuracy of $95 \%$ [28-30]. 
Fig. 5. Liver metastasis: typical appearance on CT and MRI. A Contrast-enhanced CT $60 \mathrm{~s}$ after contrast administration shows a small hypodense lesion in liver segment 5 with indistinct margins. B T2-weighted MRI more clearly depicts the same liver lesion as

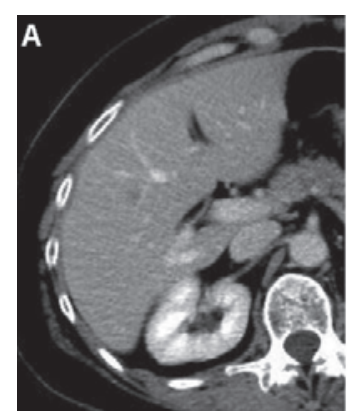

CT CE

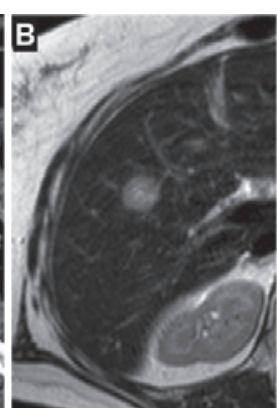

MRI: T2w

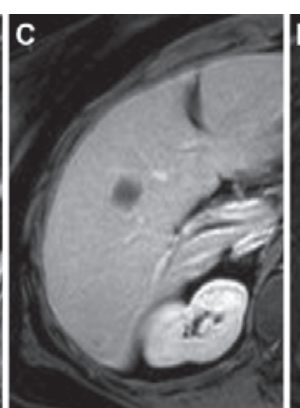

MRI: T1w CE

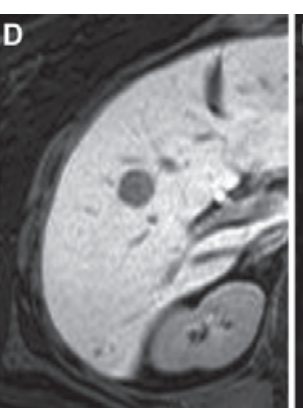

MRI: T1w Primovist®

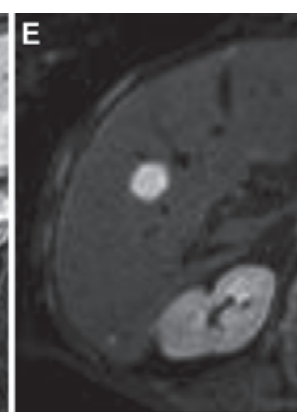

MRI: DWI

in A, exhibiting a characteristic hyperintense signal. In addition to the CT, there is also a second small liver detectable in liver segment 6 . C On dynamic contrastenhanced MRI, both liver lesions show a typical hypointense signal at the portal-venous phase. D MRI after 20 min using the liver-specific contrast agent Primovist $^{\circledR}$ more clearly depicts both liver metastases. The hypointense signal is more clearly seen due to the improved contrast to the liver parenchyma with Primovist uptake in normal functional hepatocytes. E Both liver metastases show a restricted diffusion pattern on diffusion-weighted imaging.

Table 2. Summary of imaging methods for preoperative staging (adapted from [8])

\begin{tabular}{lll}
\hline Method & $\begin{array}{l}\text { Colon } \\
\text { cancer }\end{array}$ & $\begin{array}{l}\text { Rectal } \\
\text { cancer }\end{array}$ \\
\hline Chest X-ray & $\mathrm{x}$ & $\mathrm{x}$ \\
Complete colonoscopy & $\mathrm{x}$ & $\mathrm{x}$ \\
Abdominal ultrasound & $\mathrm{x}$ & $\mathrm{x}$ \\
Abdominal computed tomgraphy & $\mathrm{x}$ & \\
Abdominal/rectal magnetic resonance imaging & & $\mathrm{x}$ \\
Endorectal ultrasound & & $\mathrm{x}^{\mathrm{a}}$ \\
Rectoscopy & & $\mathrm{x}$ \\
Positron emission tomography & & \\
\hline
\end{tabular}

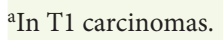

As MRI is superior to CT for the characterization of liver lesions $[3,31]$, it is recommended if unclear liver lesions are detected on CT (fig. 5) [2, 3]. Diagnostic sensitivity can be further increased when liver-specific contrast agents (e.g. Primovist ${ }^{\circledR} /$ Eovist $^{\circledR}$ or MultiHance ${ }^{\circledR}$ ) are administered [31].

\section{Imaging-Guided Therapeutic Procedures}

\section{Radiofrequency Ablation and Microwave Ablation}

Radiofrequency ablation (RFA) and microwave ablation (MWA) represent minimally invasive procedures aimed at destroying tumor cells in the liver by high-frequency or microwave current-induced heating. Under CT guidance, a probe is inserted transcutaneously into the tumor and high-frequency or microwave heating is applied.

This procedure is recommended for CRC patients in whom non-resectable liver metastases are present or in whom the general condition does not allow metastasis resection [2].

\section{Transarterial Chemoembolization}

Transarterial chemoembolization (TACE) is a minimally invasive procedure combining local infusion of chemotherapy or drug- eluting beads (e.g. mitomycin C, irinotecan, and cisplatin) with high-dose treatment and/or selective embolization of the feeding arteries of the liver metastasis.

Currently, there are no clearly defined recommendations in the guidelines with respect to the use of TACE in patients with liver metastases of CRC.

\section{Selective Internal Radiation Therapy}

Like TACE, selective internal radiation therapy (SIRT) represents a new and developing minimally invasive technique for treating non-resectable liver tumors. It involves a single delivery of ${ }^{90} \mathrm{yt}-$ trium microspheres into the hepatic artery, and potential preferred uptake into liver tumors is achieved due to their predominant hepatic arterial blood supply [32].

Due to the current lack of larger clinical studies, SIRT is recommended for the treatment of disseminated liver metastases only in those CRC patients lacking alternative therapeutic strategies and only within clinical studies [2].

\section{Treatment Response Monitoring and Follow-Up}

\section{Treatment Response Monitoring}

Although CT and MRI can show downsizing of the tumor after radio(chemo)therapy, both methods are not accurate enough to be included in the guidelines for the routine use of local treatment response monitoring [3]. Here, the main source of error represents overstaging due to a potential fibrotic thickening of the bowel wall [3]. Diffusion-weighted MRI, however, has been shown to be sensitive for predicting a pathological complete response [33, 34], yet its clinical value in this setting remains to be determined.

Nevertheless, CT and MRI play an increasingly important role in the assessment of treatment response in metastatic CRC, especially within clinical trials. In 2000, the Response Evaluation Criteria in Solid Tumors (RECIST 1.0) were proposed for evaluating treatment response [35], and a revised version was published in 2009 (RECIST 1.1) [36, 37]. These criteria are now routinely used for the evaluation of treatment response in clinical CRC studies, 


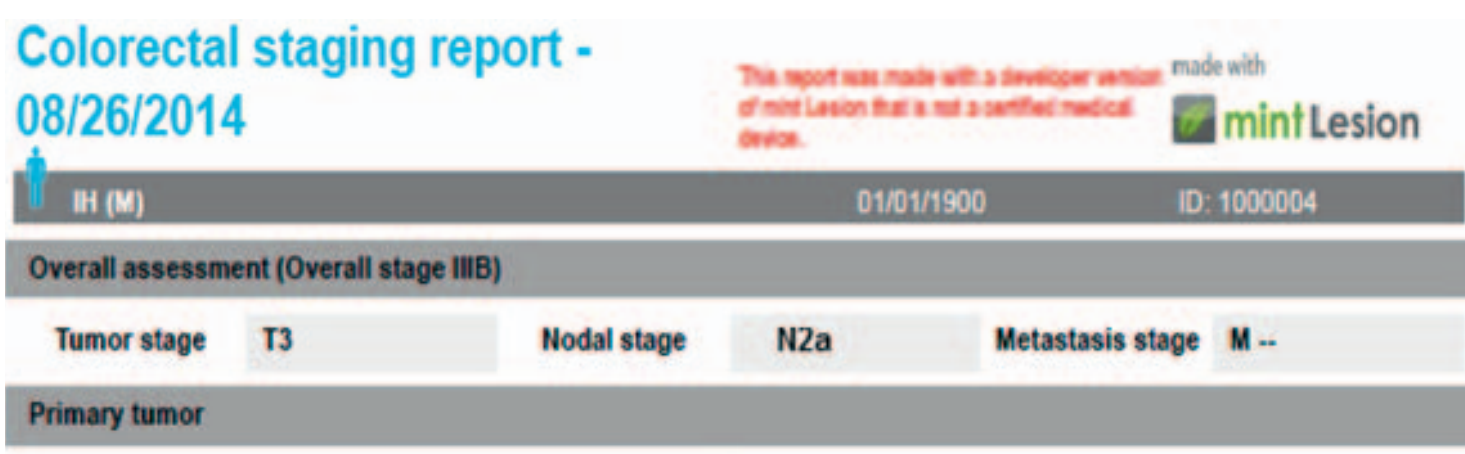

Fig. 6. Modern structured radiological report for cTNM staging of CRC including screen shots of crucial tumor information using dedicated oncology software (e.g. mint Lesion $^{\mathrm{TM}}$.

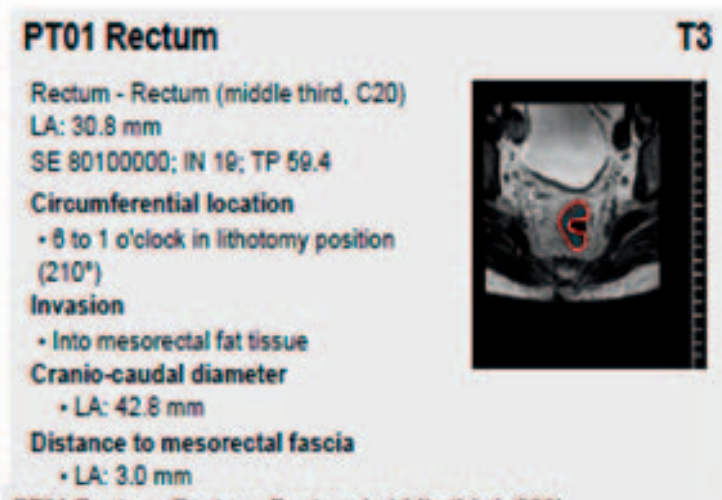

PT01 Rectum, Rectum, Rectum (middle third, C20)

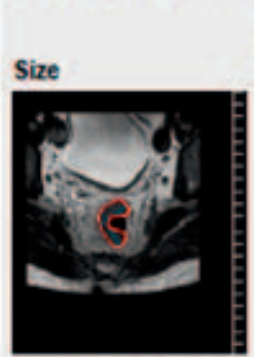

LA: $\overline{30.8} \mathrm{~mm}$

SA: $27.8 \mathrm{~mm}$

Area: $522.8 \mathrm{~mm} 2$

SE 80100000 ;

IN 19; TP 59.4

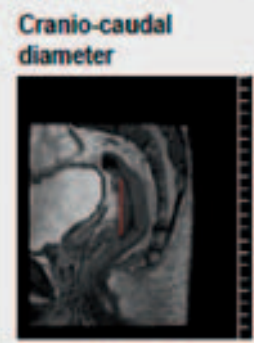

$\overline{42.8 \mathrm{~mm}}$

SE 50100000

IN $13 ;$ TP 39.6
Distance to mesorectal fascia

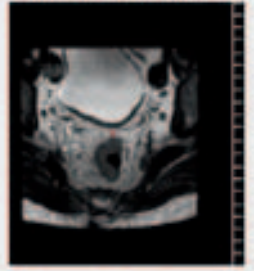

$\overline{3.0 \mathrm{~mm}}$ SE 80100000; IN 19; TP 59.4
Tumor stage: T3

Distance to anus

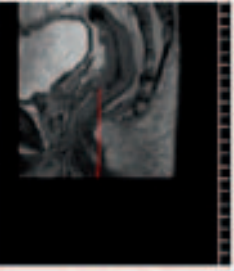

Circumferential location - 6 to 1 o'clock in lithotomy position $\left(210^{\prime}\right)$

Invasion

- Into mesorectal fat tissue and they may also make their way into clinical routine in the future management of CRC patients.

\section{Follow-Up}

All radiological imaging methods used for staging are principally also applicable to patient follow-up after treatment. There is, however, only poor evidence for a routine use of ultrasound, chest X-ray, CT, MRI, or FDG PET-CT in patients after CRC [2].

Nevertheless, chest X-ray is recommended for annual follow-up of patients with rectal cancer in stages II and III within the first 5 years after treatment [2]. There is no evidence for routine use of chest X-ray in patients with colon cancer.

The German S3 guidelines recommend abdominal ultrasound for follow-up in order to detect liver metastases, although the authors of this review admit that its routine use is not uncontroversial due to the known varying sensitivity (53-82\%) in detecting liver metastases [2,38]. Since 2013, the American Society of Clinical On- cology (ASCO) recommends an annual abdominal CT for the first 3 years after treatment [39]. However, a routine use of CT for patient follow-up is discussed controversially in the literature. According to the German S3 guidelines, this recommendation is based on sparse data. Thus, the advisory board of the German S3 guideline argues against a routine use of CT for patient follow-up [2].

In the case of suspected recurrence and unclear findings at CT and/or MRI, further ${ }^{18} \mathrm{~F}$-FDG PET-CT might be helpful in the detection of local recurrence and metastatic disease. However, ${ }^{18} \mathrm{~F}$ FDG PET-CT should not be performed within 4 weeks after systemic tumor therapy [2].

\section{Structured Reporting}

Structured radiological reporting for tumor staging and followup is recommended in varying guidelines [2-5]. However, at least 
the description of the exact tumor location and length, clinical T stage and any tumor deposits within the mesorectum, involvement of the MRF including the shortest distance $(\mathrm{mm})$ between the tumor and MRF, clinical N stage including any suspicious extramesorectal lymph nodes, and clinical $\mathrm{M}$ stage is requested. For surgical planning, further information, e.g. circumferential location of the tumor, might be warranted.

Currently, there is a rapidly increasing number of available structured reporting templates, such as $w w w$.radreport.org from the RSNA reporting initiative, and modern software solutions to be found (fig. 6).

\section{Conclusions}

Radiological imaging plays an important role in primary diagnostics, staging, evaluation of treatment response, follow-up, and even for minimally invasive interventions. CT and MRI are embedded in national and international guidelines and structured reporting is strongly recommended.

\section{Disclosure Statement}

B. Baeßler, D. Maintz, T. Persigehl: Nothing to disclose.

\section{References}

1 Gollub MJ, Schwartz LH, Akhurst T: Update on colorectal cancer imaging. Radiol Clin North Am 2007;45: 85-118.

- Pox C, Aretz S, Bischoff S, et al: S3-Leitlinie Kolorektales Karzinom Version 1.0 - Juni 2013 AWMF-Registernummer: 021/007OL. Z Gastroenterol 2013;51:753854.

3 van de Velde CJH, Boelens PG, Borras JM, et al: EURECCA colorectal: multidisciplinary management: European consensus conference colon \& rectum. Eur J Cancer 2014;50:1.e1-1.e34.

4 Glimelius B, Tiret E, Cervantes A, Arnold D; ESMO Guidelines Working Group: Rectal cancer: ESMO Clinical Practice Guidelines for diagnosis, treatment and follow-up. Ann Oncol 2013;24(suppl 6):vi81-88.

5 Beets-Tan RGH, Lambregts DMJ, Maas M, et al: Magnetic resonance imaging for the clinical management of rectal cancer patients: recommendations from the 2012 European Society of Gastrointestinal and Abdominal Radiology (ESGAR) consensus meeting. Eur Radiol 2013;23:2522-2531.

6 de Haan MC, van Gelder RE, Graser A, Bipat S, Stoker J: Diagnostic value of CT-colonography as compared to colonoscopy in an asymptomatic screening population: a meta-analysis. Eur Radiol 2011;21:1747-1763.

7 El-Maraghi RH, Kielar AZ: CT colonography versus optical colonoscopy for screening asymptomatic patients for colorectal cancer: a patient, intervention, comparison, outcome (PICO) analysis. Acad Radiol 2009;16:564-571.

8 Vogl TJ, Schmiegel W, Pox C, et al: S3 guideline - diagnosis and treatment of colorectal carcinoma: relevance for radiologic imaging and interventions (Article in German). Rofo 2013;185:699-708.

$\checkmark 9$ Morrin MM, Farrell RJ, Raptopoulos V, McGee JB, Bleday R, Kruskal JB: Role of virtual computed tomographic colonography in patients with colorectal cancers and obstructing colorectal lesions. Dis Colon Rectum 2000;43:303-311.

10 Kim CK, Kim SH, Choi D, et al: Comparison between 3-T magnetic resonance imaging and multi-detector row computed tomography for the preoperative evaluation of rectal cancer. J Comput Assist Tomogr 2007; 31:853-859.

11 Beets-Tan RG, Beets GL, Vliegen RF, et al: Accuracy of magnetic resonance imaging in prediction of tumourfree resection margin in rectal cancer surgery. Lancet 2001;357:497-504.

12 Brown G, Richards CJ, Newcombe RG, et al: Rectal carcinoma: thin-section MR imaging for staging in 28 patients. Radiology 1999;211:215-222.

$\checkmark 13$ MERCURY Study Group: Extramural depth of tumor invasion at thin-section MR in patients with rectal cancer: results of the MERCURY study. Radiology 2007; 243:132-139.
14 Maizlin ZV, Brown JA, So G, et al: Can CT replace MRI in preoperative assessment of the circumferential resection margin in rectal cancer? Dis Colon Rectum 2010;53:308-314

15 Smith N, Brown G: Preoperative staging of rectal cancer. Acta Oncol 2008;47:20-31.

16 Merkel S, Mansmann U, Siassi M, Papadopoulos T, Hohenberger W, Hermanek P: The prognostic inhomogeneity in $\mathrm{pT} 3$ rectal carcinomas. Int J Colorectal Dis 2001;16:298-304.

17 Taylor FGM, Quirke P, Heald RJ, et al: One millimetre is the safe cut-off for magnetic resonance imaging prediction of surgical margin status in rectal cancer. Br J Surg 2011;98:872-879.

18 Glimelius B, Beets-Tan R, Blomqvist L, et al: Mesorectal fascia instead of circumferential resection margin in preoperative staging of rectal cancer. J Clin Oncol 2011; 29:2142-2143.

19 Gearhart SL, Frassica D, Rosen R, Choti M, Schulick R, Wahl R: Improved staging with pretreatment positron emission tomography/computed tomography in low rectal cancer. Ann Surg Oncol 2006;13:397-404.

20 Ahmetoğlu A, Cansu A, Baki D, et al: MDCT with multiplanar reconstruction in the preoperative local staging of rectal tumor. Abdom Imaging 2011;36:3137.

21 Winter L, Bruhn H, Langrehr J, Neuhaus P, Felix R, Hänninen LE: Magnetic resonance imaging in suspected rectal cancer: determining tumor localization, stage, and sphincter-saving resectability at 3-Teslasustained high resolution. Acta Radiol 2007;48:379387.

22 Smith NJ, Barbachano Y, Norman AR, Swift RI, Abulafi AM, Brown G: Prognostic significance of magnetic resonance imaging-detected extramural vascular invasion in rectal cancer. Br J Surg 2008;95:229-236.

23 Kim DJ, Kim JH, Ryu YH, Jeon TJ, Yu J-S, Chung J-J: Nodal staging of rectal cancer: high-resolution pelvic MRI versus ${ }^{18} \mathrm{~F}$-FDGPET/CT. J Comput Assist Tomogr 2011;35:531-534.

24 Kim JH, Beets GL, Kim M-J, Kessels AGH, Beets-Tan RGH: High-resolution MR imaging for nodal staging in rectal cancer: are there any criteria in addition to the size? Eur J Radiol 2004;52:78-83.

25 Takahara T, Imai Y, Yamashita T, Yasuda S, Nasu S, van Cauteren M: Diffusion weighted whole body imaging with background body signal suppression (DWIBS): technical improvement using free breathing, STIR and high resolution 3D display. Radiat Med 2004; 22:275-282.

26 Manenti G, Cicciò C, Squillaci E, et al: Role of combined DWIBS/3D-CE-T1w whole-body MRI in tumor staging: comparison with PET-CT. Eur J Radiol 2012; 81:1917-1925.
7 Schmidt GP, Reiser MF, Baur-Melnyk A: Whole-body MRI for the staging and follow-up of patients with metastasis. Eur J Radiol 2009;70:393-400.

28 Leufkens AM, van den Bosch MAAJ, van Leeuwen MS, Siersema PD: Diagnostic accuracy of computed tomography for colon cancer staging: a systematic review. Scand J Gastroenterol 2011;46:887-894.

29 Dighe S, Blake H, Koh M-D, et al: Accuracy of multidetector computed tomography in identifying poor prognostic factors in colonic cancer. Br J Surg 2010;97: 1407-1415.

30 Dighe S, Purkayastha S, Swift I, et al: Diagnostic precision of CT in local staging of colon cancers: a metaanalysis. Clin Radiol 2010;65:708-719.

31 Floriani I, Torri V, Rulli E, et al: Performance of imaging modalities in diagnosis of liver metastases from colorectal cancer: a systematic review and meta-analysis. J Magn Reson Imaging 2010;31:19-31.

32 Stubbs RS, Wickremesekera SK: Selective internal radiation therapy (SIRT): a new modality for treating patients with colorectal liver metastases. HPB (Oxford) 2004;6:133-139.

33 Curvo-Semedo L, Lambregts DMJ, Maas M, Beets GL, Caseiro-Alves F, Beets-Tan RGH: Diffusion-weighted MRI in rectal cancer: apparent diffusion coefficient as a potential noninvasive marker of tumor aggressiveness. J Magn Reson Imaging 2012;35:1365-1371.

34 Lambregts DMJ, Vandecaveye V, Barbaro B, et al: Diffusion-weighted MRI for selection of complete responders after chemoradiation for locally advanced rectal cancer: a multicenter study. Ann Surg Oncol 2011; 18:2224-2231.

35 Therasse P, Arbuck SG, Eisenhauer EA, et al: New guidelines to evaluate the response to treatment in solid tumors. European Organization for Research and Treatment of Cancer, National Cancer Institute of the United States, National Cancer Institute of Canada. J Natl Cancer Inst 2000;92:205-216.

36 Eisenhauer EA, Therasse P, Bogaerts J, et al: New response evaluation criteria in solid tumours: revised RECIST guideline (version 1.1). Eur J Cancer 2009; 45: 228-247.

37 Spiro J, Maintz D, Persigehl T: Response criteria for malignant melanoma: RECIST and irRC (Article in German). Radiologe 2015;55:127-135.

38 Mäkelä JT, Laitinen SO, Kairaluoma MI: Five-year follow-up after radical surgery for colorectal cancer. Results of a prospective randomized trial. Arch Surg 1995; 130:1062-1067.

39 Meyerhardt JA, Mangu PB, Flynn PJ, et al: Follow-up care, surveillance protocol, and secondary prevention measures for survivors of colorectal cancer: American Society of Clinical Oncology clinical practice guideline endorsement. J Clin Oncol 2013;31:4465-4470. 